Acta Crystallographica Section E

Structure Reports

Online

ISSN 1600-5368

\section{Ray J. Butcher, ${ }^{a *}$}

H. S. Yathirajan, ${ }^{\text {b }}$ A. Mithun,

B. Narayana ${ }^{c}$ and B. K. Sarojini ${ }^{d}$

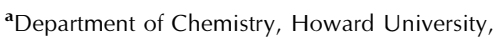
525 College Street NW, Washington, DC 20059, USA, 'bepartment of Studies in Chemistry, University of Mysore,

Manasagangotri, Mysore 570 006, India, cDepartment of Chemistry, Mangalore University, Mangalagangotri 574 199, India, and ${ }^{\mathbf{d}}$ Department of Chemistry, P. A. College of Engineering, Nadupadavu, Mangalore 574 153, India

Correspondence e-mail:

raymond.butcher@nrl.navy.mil

\author{
Key indicators \\ Single-crystal X-ray study \\ $T=446 \mathrm{~K}$ \\ Mean $\sigma(\mathrm{C}-\mathrm{C})=0.003 \AA$ \\ $R$ factor $=0.040$ \\ $w R$ factor $=0.115$ \\ Data-to-parameter ratio $=19.2$
}

For details of how these key indicators were automatically derived from the article, see http://journals.iucr.org/e.
(C) 2006 International Union of Crystallography All rights reserved

\title{
Chalcone and its hydroxobromo derivative: a 1:1 mixed crystal containing chalcone and 2-bromo-3-hydroxy-1-(4-methylphenyl)-3- [4-(methylsulfanyl)phenyl]propan-1-one
}

In the structure of a mixed crystal, $\mathrm{C}_{17} \mathrm{H}_{17} \mathrm{BrO}_{2} \mathrm{~S} \cdot \mathrm{C}_{17} \mathrm{H}_{16} \mathrm{OS}$, containing chalcone and 2-bromo-3-hydroxy-1-(4-methylphenyl)-3-[4-(methylsulfanyl)phenyl]propan-1-one, the two molecules are linked by a strong hydrogen bond between the alcohol $\mathrm{H}$ atom of 2-bromo-3-hydroxy-1-(4-methylphenyl)-3-[4-(methylsulfanyl)phenyl]propan-1-one and the ketone group of chalcone.

\section{Comment}

There is currently great demand for large and high quality ferroelectric or piezoelectric single crystals with minimum defects and inhomogenities. An important goal of crystal growth is the improvement of microscopic and macroscopic homogeneity, which is a necessity for any application. Different types of crystals being used are semiconductor crystals, oxide crystals, alkali halide crystals and non-linear optical (NLO) crystals. The NLO effect in organic compounds originates from a strong donor-acceptor intermolecular interaction, a delocalized $\pi$-electron system and the ability to crystallize in a non-centrosymmetric structure. Among several organic compounds reported for their NLO properties, chalcone derivatives are prominent materials for their excellent blue light transmittance and good crystallizability. They provide the configuration necessary to show NLO activity, with two planar rings connected through a conjugated double bond (Goto et al., 1991; Uchida et al., 1998; Tam et al., 1989; Indira et al., 2002). From a search of noncentrosymmetric chalcone derivatives in the Cambridge Structural Database (ConQuest Version 1.8; Allen, 2002), it seems that a necessary but not sufficient condition (Teh et al., 2006) is substitution on either of the phenyl rings in the para position (Rabinovich, 1970; Arai et al., 1994; Rabinovich \& Shakked, 1974; Ravishankar et al., 2005; Rabinovich \& Schmidt, 1970; Li et al., 1992; Gupta et al., 2002; Turowska-Tyrk et al., 2003; Zheng et al., 1992; Patil et al., 2006). It is speculated that, in order to improve the activity, more bulky substituents should be introduced to increase the spontaneous polarization of a noncentrosymmetric crystal structure (Fichou et al., 1988). The molecular hyperpolarizability, $\beta$, is strongly influenced not only by the electronic effect but also by the steric effect of the substituents (Cho et al., 1996).

In a continuation of our quest to synthesize new materials which could find use in the photonics industry, we have synthesized a new chalcone. However, chalcone derivatives often have low melting points, which can be a drawback for the application of these crystals in optical instruments. Chalcone dibromides usually have higher melting points and are thermally stable. With this in mind, we wanted to prepare a new dibromochalcone starting from 1-(4-methylphenyl)-3-[4-
Received 21 February 2006 Accepted 11 May 2006 
(methylsulfanyl)phenyl]prop-2-en-1-one in chloroform using commercial-grade bromine. However, single-crystal X-ray analysis revealed that compound (I) is a mixed crystal of

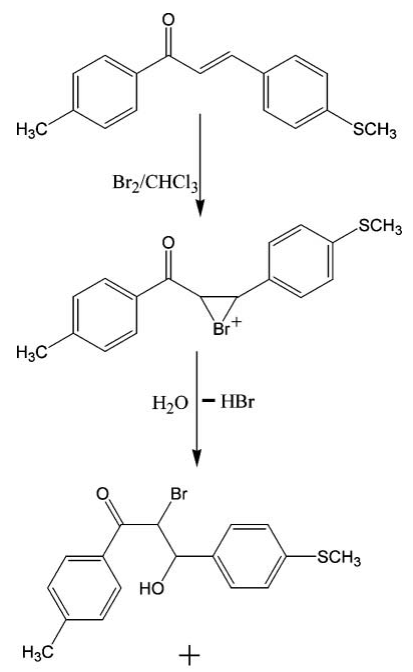<smiles>COc1ccc(/C=C/C(=O)c2ccc(C)cc2)cc1</smiles>

(I)

chalcone and 2-bromo-3-hydroxy-1-(4-methylphenyl)-3-[4(methylsulfanyl)phenyl]propan-1-one, as the bromination reaction is incomplete. The hydroxobromo derivative of chalcone is formed by the cleavage of a cyclic bromonium intermediate by nucleophilic attack of water on the bromonium ion instead of on the bromide ion (see scheme). Thus, some of the chalcone remains unreacted, giving a mixed crystal with 2-bromo-3-hydroxy-1-(4-methylphenyl)-3-[4(methylsulfanyl)phenyl]propan-1-one linked by hydrogen bonding. Bromination was carried out in commercial-grade

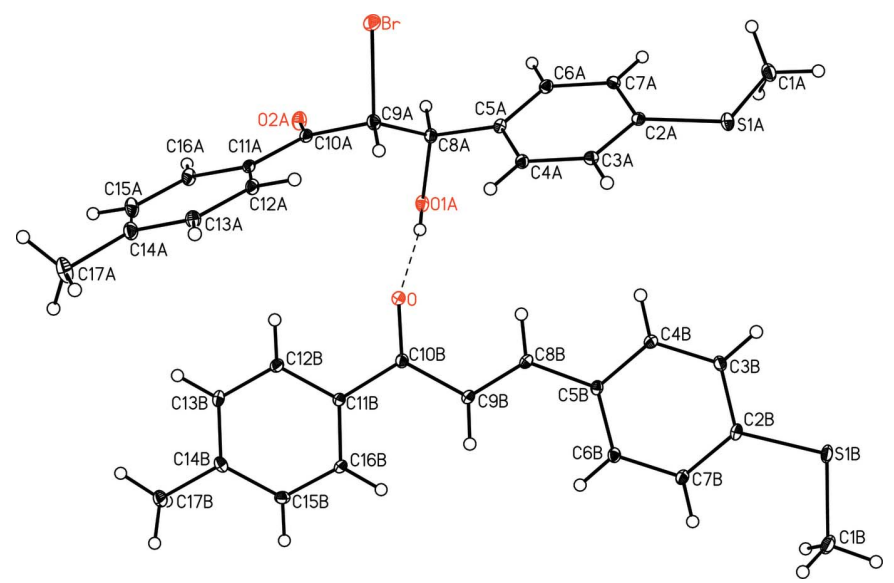

Figure 1

A view showing the two components of (I), linked by a strong hydrogen bond (dashed line) between the alcohol $\mathrm{H}$ atom of 2-bromo-3-hydroxy-1(4-methylphenyl)-3-[4-(methylthio)phenyl]propan-1-one and the ketone group of chalcone. Displacement ellipsoids are drawn at the $20 \%$ probability level.

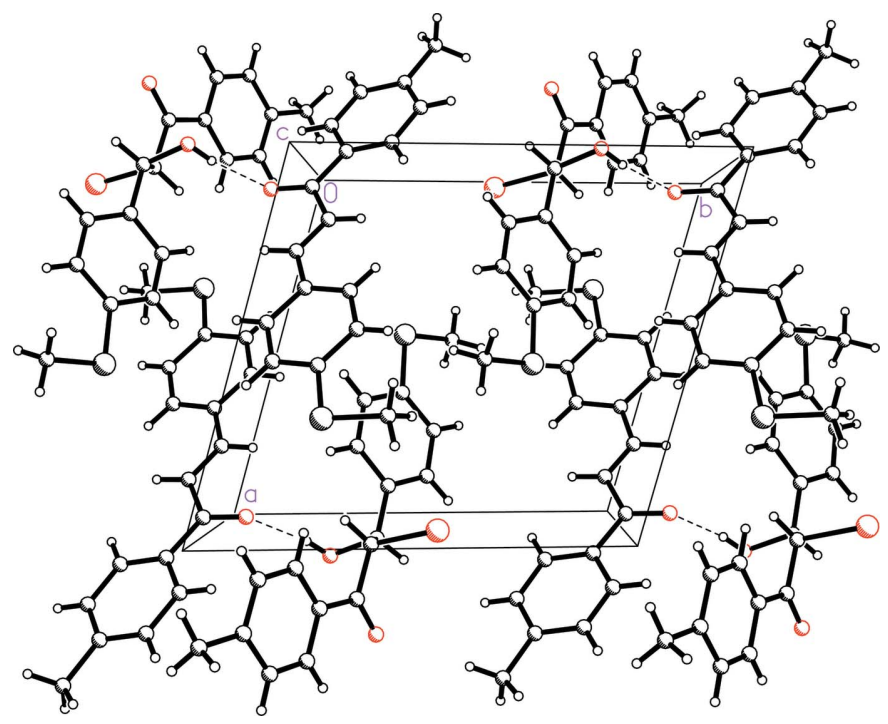

Figure 2

The molecular packing, viewed down the $c$ axis. Hydrogen bonds are shown as dashed lines

bromine in chloroform, and moisture was not excluded. The reduction of the double bond in the chalcone derivative is confirmed by the structural results, which show the addition of an $-\mathrm{OH}$ function to $\mathrm{C} 8 A$, and by the lengthening of the $\mathrm{C} 8-$ C9 bond from 1.344 (3) for $\mathrm{C} 8 B-\mathrm{C} 9 B$ to 1.505 (3) $\AA$ for $\mathrm{C} 8 A-\mathrm{C} 9 A$ and the change in the angles about $\mathrm{C} 8 A$ and $\mathrm{C} 9 A$ from trigonal $\left(s p^{2}\right)$ to tetrahedral $\left(s p^{3}\right)$ values.

\section{Experimental}

To a solution of 1-(4-methylphenyl)-3-[4-(methylsulfanyl)phenyl]prop-2-en-1-one $(2.68 \mathrm{~g}, 0.01 \mathrm{~mol})$ in chloroform $(50 \mathrm{ml})$, bromine $(1.60 \mathrm{~g}, 0.01 \mathrm{~mol})$ in chloroform $(20 \mathrm{ml})$ was added slowly with stirring. After the completion of the addition of the bromine solution, the reaction mixture was stirred for $24 \mathrm{~h}$. Excess chloroform was distilled off under reduced pressure. The solid obtained was dried and recrystallized from acetone.

\section{Crystal data}

$\mathrm{C}_{17} \mathrm{H}_{17} \mathrm{BrO}_{2} \mathrm{~S} \cdot \mathrm{C}_{17} \mathrm{H}_{16} \mathrm{OS}$

$M_{r}=633.63$

Triclinic, $P \overline{1}$

$a=10.5026(15) \AA$

$b=11.4926(17) \AA$

$c=13.1326(19) \AA$

$\alpha=97.173(3)^{\circ}$

$\beta=98.157(2)^{\circ}$

$\gamma=104.125(2)^{\circ}$

\section{Data collection}

Bruker APEXII CCD area-detector diffractometer

$\varphi$ and $\omega$ scans

Absorption correction: multi-scan (SADABS; Sheldrick, 1996)

$T_{\min }=0.774, T_{\max }=1.000$

(expected range $=0.451-0.583$ )

$$
\begin{aligned}
& V=1500.5(4) \AA^{3} \\
& Z=2 \\
& D_{x}=1.402 \mathrm{Mg} \mathrm{m}^{-3} \\
& \text { Mo Ko radiation } \\
& \mu=1.54 \mathrm{~mm}^{-1} \\
& T=446(2) \mathrm{K} \\
& \text { Chunk, colourless } \\
& 0.50 \times 0.40 \times 0.35 \mathrm{~mm}
\end{aligned}
$$

26944 measured reflections 7025 independent reflections 5636 reflections with $I>2 \sigma(I)$ $R_{\text {int }}=0.070$

$\theta_{\max }=27.9^{\circ}$ 


\section{Refinement}

Refinement on $F^{2}$

$R\left[F^{2}>2 \sigma\left(F^{2}\right)\right]=0.040$

$w R\left(F^{2}\right)=0.115$

$S=1.06$

7025 reflections

366 parameters
$\mathrm{H}$ atoms treated by a mixture of independent and constrained refinement

$w=1 /\left[\sigma^{2}\left(F_{\mathrm{o}}{ }^{2}\right)+(0.0705 P)^{2}\right]$

where $P=\left(F_{\mathrm{o}}{ }^{2}+2 F_{\mathrm{c}}{ }^{2}\right) / 3$

$(\Delta / \sigma)_{\max }=0.001$

$\Delta \rho_{\max }=0.84{\mathrm{e} \AA^{-3}}^{-3}$

$\Delta \rho_{\min }=-0.62 \mathrm{e}^{-3}$

\section{Table 1}

Selected geometric parameters $\left(\AA{ }^{\circ}\right)$.

\begin{tabular}{llll}
\hline $\mathrm{Br}-\mathrm{C} 9 A$ & $1.978(2)$ & $\mathrm{C} 5 A-\mathrm{C} 8 A$ & $1.511(3)$ \\
$\mathrm{S} 1 A-\mathrm{C} 2 A$ & $1.762(2)$ & $\mathrm{C} 8 A-\mathrm{C} 9 A$ & $1.505(3)$ \\
$\mathrm{S} 1 A-\mathrm{C} 1 A$ & $1.802(2)$ & $\mathrm{C} 9 A-\mathrm{C} 10 A$ & $1.520(3)$ \\
$\mathrm{S} 1 B-\mathrm{C} 2 B$ & $1.762(2)$ & $\mathrm{C} 10 A-\mathrm{C} 11 A$ & $1.490(3)$ \\
$\mathrm{S} 1 B-\mathrm{C} 1 B$ & $1.796(3)$ & $\mathrm{C} 5 B-\mathrm{C} 8 B$ & $1.459(3)$ \\
$\mathrm{O}-\mathrm{C} 10 B$ & $1.236(3)$ & $\mathrm{C} 8 B-\mathrm{C} 9 B$ & $1.344(3)$ \\
$\mathrm{O} 1 A-\mathrm{C} 8 A$ & $1.478(3)$ & $\mathrm{C} 9 B-\mathrm{C} 10 B$ & $1.477(3)$ \\
$\mathrm{O} 2 A-\mathrm{C} 10 A$ & $1.225(3)$ & $\mathrm{C} 10 B-\mathrm{C} 11 B$ & $1.492(3)$ \\
& & & \\
$\mathrm{O} 1 A-\mathrm{C} 8 A-\mathrm{C} 9 A$ & $106.17(17)$ & $\mathrm{C} 6 B-\mathrm{C} 5 B-\mathrm{C} 4 B$ & $118.2(2)$ \\
$\mathrm{O} 1 A-\mathrm{C} 8 A-\mathrm{C} 5 A$ & $110.92(18)$ & $\mathrm{C} 6 B-\mathrm{C} 5 B-\mathrm{C} 8 B$ & $123.9(2)$ \\
$\mathrm{C} 9 A-\mathrm{C} 8 A-\mathrm{C} 5 A$ & $113.62(19)$ & $\mathrm{C} 4 B-\mathrm{C} 5 B-\mathrm{C} 8 B$ & $118.0(2)$ \\
$\mathrm{C} 8 A-\mathrm{C} 9 A-\mathrm{C} 10 A$ & $112.66(19)$ & $\mathrm{C} 9 B-\mathrm{C} 8 B-\mathrm{C} 5 B$ & $128.1(2)$ \\
$\mathrm{C} 8 A-\mathrm{C} 9 A-\mathrm{Br}$ & $109.50(15)$ & $\mathrm{C} 8 B-\mathrm{C} 9 B-\mathrm{C} 10 B$ & $119.8(2)$ \\
$\mathrm{C} 10 A-\mathrm{C} 9 A-\mathrm{Br}$ & $105.16(15)$ & $\mathrm{O}-\mathrm{C} 10 B-\mathrm{C} 9 B$ & $120.9(2)$ \\
$\mathrm{O} 2 A-\mathrm{C} 10 A-\mathrm{C} 11 A$ & $121.2(2)$ & $\mathrm{O}-\mathrm{C} 10 B-\mathrm{C} 11 B$ & $119.5(2)$ \\
$\mathrm{O} 2 A-\mathrm{C} 10 A-\mathrm{C} 9 A$ & $119.5(2)$ & $\mathrm{C} 9 B-\mathrm{C} 10 B-\mathrm{C} 11 B$ & $119.67(19)$ \\
$\mathrm{C} 11 A-\mathrm{C} 10 A-\mathrm{C} 9 A$ & $119.30(19)$ & & \\
\hline
\end{tabular}

Table 2

Hydrogen-bond geometry $\left(\AA{ }^{\circ}\right)$.

\begin{tabular}{lllll}
\hline$D-\mathrm{H} \cdots A$ & $D-\mathrm{H}$ & $\mathrm{H} \cdots A$ & $D \cdots A$ & $D-\mathrm{H} \cdots A$ \\
\hline $\mathrm{O} 1 A-\mathrm{H} 1 A \cdots \mathrm{O}$ & 0.82 & 1.95 & $2.760(2)$ & 170 \\
\hline
\end{tabular}

All $\mathrm{H}$ atoms were initially located in a difference Fourier map. The methyl $\mathrm{H}$ atoms were then constrained to an ideal geometry, with $\mathrm{C}-$ $\mathrm{H}$ distances of $0.98 \AA$ and $U_{\text {iso }}(\mathrm{H})=1.5 U_{\text {eq }}(\mathrm{C})$, but each group was allowed to rotate freely about its $\mathrm{C}-\mathrm{C}$ bond. The $\mathrm{H}$ attached to $\mathrm{O} 1 A$ was located in a difference Fourier map and idealized with $\mathrm{O}-\mathrm{H}=$ $0.82 \AA$ and $U_{\text {iso }}(\mathrm{H})=1.5 U_{\text {eq }}(\mathrm{O})$. All other $\mathrm{H}$ atoms were placed in geometrically idealized positions and constrained to ride on their parent atoms, with $\mathrm{C}-\mathrm{H}$ distances in the range $0.95-1.00 \AA$ and $U_{\text {iso }}(\mathrm{H})=1.2 U_{\text {eq }}(\mathrm{C})$.

Data collection: SMART (Bruker, 1998); cell refinement: SAINTPlus (Bruker, 1999); data reduction: SAINT-Plus; program(s) used to solve structure: SHELXS97 (Sheldrick, 1990); program(s) used to refine structure: SHELXL97 (Sheldrick, 1997a); molecular graphics: SHELXTL (Sheldrick, 1997b); software used to prepare material for publication: SHELXTL.

One of the authors (BKS) thanks AICTE, Government of India, New Delhi, for financial assistance under the Career Award for Young Teachers (CAYT) scheme.

\section{References}

Allen, F. H. (2002). Acta Cryst. B58, 380-388.

Arai, H., Higashigaki, Y., Goto, M. \& Yano, S. (1994). Jpn. J. Appl. Phys. 33, 5755-5758.

Bruker (1998). SMART. Bruker AXS Inc., Madison, Wisconsin, USA.

Bruker (1999). SAINT-Plus and SHELXTL. Bruker AXS Inc., Madison, Wisconsin, USA.

Cho, B. R., Je, J. T., Kim, H. S., Jean, S. J., Song, O. K. \& Wang, C. H. (1996). Bull. Korean Chem. Soc. 17, 693-695.

Fichou, D., Watanabe, T., Takeda, T., Miyata, S., Goto, Y. \& Nakayama, M. (1988). Jpn. J. Appl. Phys. 27, 429-430.

Goto, Y., Hayashi, A., Kimura, Y. \& Nakayama, M. (1991). J. Cryst. Growth, 108, 688-698.

Gupta, S., Henk, S., Kees, G., Yeap, G.-Y., Susanti, I., Mahmood, W. A. K. W. \& Gupta, P. S. (2002). Z. Kristallogr. New Cryst. Struct. 217, 503.

Indira, J., Karat, P. P. \& Sarojini, B. K. (2002). J. Cryst. Growth, 242, 209-214.

Li, Z., Pa, F. \& Su, G. (1992). Acta Cryst. C48, 712-714.

Patil, P. S., Teh, J. B.-J., Fun, H.-K., Razak, I. A. \& Dharmaprakash, S. M. (2006). Acta Cryst. E62, o896-o898.

Rabinovich, D. (1970). J. Chem. Soc. B, pp. 11-16.

Rabinovich, D. \& Schmidt, G. M. J. (1970). J. Chem. Soc. B, pp. 6-10.

Rabinovich, D. \& Shakked, Z. (1974). Acta Cryst. B30, 2829-2834.

Ravishankar, T., Chinnakali, K., Nanjundan, S., Selvam, P., Fun, H.-K. \& Yu, X.-L. (2005). Acta Cryst. E61, o405-0407.

Sheldrick, G. M. (1990). Acta Cryst. A46, 467-473.

Sheldrick, G. M. (1996). SADABS. University of Göttingen, Germany.

Sheldrick, G. M. (1997a). SHELXL97. University of Göttingen, Germany.

Sheldrick, G. M. (1997b). SHELXTL. Version 5.10. Bruker AXS Inc., Madison, Wisconsin, USA.

Tam, W., Guerin, B., Calabrese, J. C. \& Stevenson, S. H. (1989). Chem. Phys. Lett. 154, 93-96.

Teh, J. B.-J., Patil, P. S., Fun, H.-K., Razak, I. A. \& Dharmaprakash, S. M. (2006). Acta Cryst. E62, o890-o892.

Turowska-Tyrk, I., Grzesniak, K., Trzop, E. \& Zych, T. (2003). J. Solid State Chem. 174, 459-465.

Uchida, T., Kozawa, K., Sakai, T., Aoki, M., Yoguchi, H., Abduryim, A. \& Watanabe, Y. (1998). Mol. Cryst. Liq. Cryst. 315, 135-140.

Zheng, J., Zhang, D., Sheng, P., Wang, H. \& Yao, X. (1992). Yingyong Huaxue (Chin. J. Appl. Chem.), 9, 66-69. (In Chinese). 